\title{
Awareness of Reading Strategy Use of Indian ESL Students and the Relationship with Reading Comprehension Achievement
}

\author{
Madhumathi, P. ${ }^{1} \&$ Arijit Ghosh ${ }^{2}$ \\ ${ }^{1}$ School of Social Sciences and Languages, VIT University, India \\ ${ }^{2}$ Department of English, Pondicherry University, India \\ Correspondence: Madhumathi, P., School of Social Sciences and Languages, VIT University, Vellore, India. \\ E-mail: madhuhoney87@gmail.com
}

Received: October 8, 2012 Accepted: October 26, 2012 Online Published: October 31, 2012

doi:10.5539/elt.v5n12p131 URL: http://dx.doi.org/10.5539/elt.v5n12p131

\begin{abstract}
This paper reports findings from the study that assessed the first year Indian ESL students' awareness of reading strategy use. It also investigated the relationship that exists between reading strategy use and the reading comprehension achievements of the Indian ESL students. The study utilized two instruments such as SORS and RCT which is the modified version of TOEFL reading comprehension. The reading strategies are classified into the global, problem solving and supporting. The results showed that the students employed problem solving strategy the most and they least preferred to use global strategies. The difference in the strategy use is statistically significant except for supporting strategy. The high proficiency students over performed the middle and the low proficiency students in terms of strategy use. Overall, the reading strategy use moderately correlated with the reading comprehension achievement of the Indian students. There is a significant difference in the use of strategy by Gender, in which the female students reported using more strategy than that of male students. The pedagogic implications of these findings are discussed in terms of practices in the Indian society. Thus, the study identifies the Indian ESL students, reading strategy preferences and suggests remedial measures for classroom teaching.
\end{abstract}

Keywords: academic reading, ESL, reading comprehension, reading strategy use, SORS

\section{Introduction}

Reading is an essential skill that ensures success in academic learning (Alderson, 1984). Research on reading reports strong support for the positive relationship between the students' reading process and their ability to comprehend what they are reading. Further, reading process and reading ability will directly help the students to excel academically (Alderson, 1984, Carrell, 1991; Clarke, 1979; Cziko, 1978). Second language reading research points out that reading is an interactive, meaning building process, in which the readers employ multitude of strategies to grasp information from various available sources. L2 researches on reading have made several efforts to identify the variety of reading strategies that contribute to successful comprehension. The studies during the last two decades on reading have profiled an extensive range of reading strategies used by readers. The reading strategy list comprises of well-known items like skimming, scanning, and inferring to the more recently conceptualized ones such as stimulating schemata, identifying text structure, using mental images, envisaging, asking questions, monitoring comprehension, assessing strategy use (Anderson, 1991; Carrell, 1989; Block, 1986; Cohen, 1990; Pressley, 2002; Zhang et al., 2008).

According to Cohen (1990), reading strategies are "those mental procedures that readers deliberately prefer to employ in accomplishing reading tasks". Garner (1987) identifies use of reading strategies as an action, or a chain of actions that a reader practices in order to make meaning in the reading process (Hudson, 2007). Hence, employing reading strategies means how readers visualize a task, what they do to construct meaning from the manuscripts, and what they do when comprehension collapses (Block, 1986, 1992; Macaro, 2001; Macaro \& Erler, 2008; Zhang, 2001).

Ever since English for Specific Purposes (ESP) course has been framed for teaching English to ESL learners, continued interest is expressed in promoting reading as a significant and workable means of language development (Susser \& Robb, 1990). Reading in English as a second language (ESL) is seriously emphasized in 
conventional L2 teaching, and so, developing instruction for teaching reading is the core of language teaching research now (Susser \& Robb, 1990). Recent instructions on reading concentrate on teaching the readers rather than teaching texts (Haas \& Flower, 1988). Thus, the contemporary methods of teaching focuses on explicit teaching of reading skills and strategies to the students, which will help them to understand the mental processes that are associated with reading like content, textual features, rhetorical elements, and cultural background (Susser \& Robb, 1990).

\section{Review of Literature}

Researches on reading strategy investigate the process involved in reading rather than comprehension ability. Garner (1987) asserts that students with sufficient knowledge of vocabulary and decoding skills also have problems while comprehending a text, which is due to lack of strategic knowledge. Sheorey and Mokhtari (2001) consider that an awareness of reading strategies and comprehension monitoring are the essential elements that a good reader shall possess. They suggest that metacognitive knowledge of the readers includes an awareness of a range of reading strategies. Flavell (1979) states that cognitive strategies include perceiving, understanding, recollecting and other skills. Metacognitive strategies are used to monitor these cognitive strategies.

McDough (1995) has identified through interpretation of think aloud data that the four categories of reading strategies may exist such as Technical aid strategy, clarification and simplification strategies, coherent detection strategies and monitoring strategies. Cheng (1998) investigated ten Taiwanese students to identify and study the types of reading strategies used by them while reading English. The analysis reports existence of two typical patterns such as "integrating" and "non-integrating" among the Taiwanese readers. The integrators are most probably employed in general or top-down kinds of reading strategies, whereas non-integrators incline to exercise local, bottom-up kinds of reading strategies. Cheng also indicates that socio-cultural factors influence the ESL students reading purposes. Depending upon the socio-cultural factors difference among students, their reading purpose varies, which results in different patterns of reading strategy use. Cheng notices that other aspects like personality, experience with strategy training, language proficiency, reading interests, and academic major also affect the students' implementation of reading strategies. Poole (2009) reports that gender had significantly influenced students' choice of reading strategy. It is reported that female students use strategies more frequently than their male counterparts (Ehrman and Oxford, 1989; Oxford, 1993; Hong-Nam and Leavell, 2006)

$\mathrm{Wu}(2002)$ examines if there is any difference in strategy use between L2 high proficiency students and L2 low proficiency students in terms of their reading awareness. Wu notices that high proficient students have more awareness to metacognitive skills and low proficient students believe in using bottom-up strategies for processing information (Chern, 1994; Cheng, 2000; Hsu, 2003). Sheorey and Mokhtari (2001) also report that good readers are aware of the strategies and know to utilize those strategies appropriately.

Chern (1994) researched on Chinese readers' metacognitive awareness while reading English. The results indicate that Chinese readers often used dictionary and they are accuracy-oriented readers. They also least used reading strategies while comprehending information or recollecting the text. Cheng (2000) also demonstrates that Taiwanese EFL college students rely on local strategies while reading English text.

Brantmeier (2002) asserts that the benefits of reading strategy use depend on how effectively readers use these strategies rather than the mere knowledge of it. Al-Nujaidi (2003) suggests think-aloud protocols and interviewing method to remediate reading strategy uses, which provide important and accurate details about the different aspects of EFL reading in Saudi Arabia. Researches that are conducted by Indian researchers on Indian students reading strategy use are few, which do not support generalization of effectiveness or success of teaching reading strategies in Indian universities. Without the knowledge of Indian students' strategy preference, it is difficult to understand the factors affecting their reading comprehension and to design reading instruction.

\section{Purpose of the Study}

Most of the studies that investigated the relationship between reading strategy use and the reading achievement were performed in settings different from India. Thus, the current research intends to find out the relationship that exists between Indian ESL students' reading strategy use and their reading comprehension achievement. The study is also interested in identifying the difference in use of strategy by gender. Therefore, Indian students' awareness of reading strategy can be identified and appropriate reading instruction can be designed for teaching.

Thus, the current study addresses the following research questions:

1) What are the primary reading strategies used by Indian university students?

2) Is there a relationship between second language reading proficiency and reading strategy use? 
3) Is there a significant difference in strategy use associated with gender?

\section{Methodology}

\subsection{Participants}

Participants in this study were 52 first year engineering students studying at a private university in south India. The sample constituted a class of students attending English language course at English language laboratory. There were 24 males and 28 females, in the age group $18-21$ at the time of data collection. All participants have received at least ten years of English instruction at school. The reading comprehension test (RCT) results revealed that there are 11 low proficiency students, 27 medium proficiency students and 14 high proficiency students. The question based on the regular extra reading habits (newspaper, magazines, novel, short story) reports that $73 \%$ of female and $38 \%$ of the male students have regular reading habits.

\subsection{Instruments}

The study has utilized two instruments such as Survey of Reading Strategy (SORS) and Reading Comprehension Test (RCT). Survey of Reading Strategy (SORS): SORS by Mokhtari and Sheorey (2002) is utilized to assess ESL students' perceived use of reading strategies. The reliability of the instrument is found to be 0.79 . This proves a reasonable degree of reliability in assessing awareness and perceived use of reading strategies among non-native / ESL students of English. Mokhtari and Sheorey (2002) have included 30 items in SORS with three subscales:

1. Global Reading Strategy (GLOB): This strategy constituted 13 items of "intentional, carefully planned techniques by which learners monitor or manage their reading (p. 4)".

2. Problem Solving Strategy (PROB): This strategy constituted 8 items, including "actions and procedures that readers use while working directly with the text. These are localized and focused techniques used when problems develop in understanding textual information (p. 4)".

3. Support Strategy (SUP): This strategy constituted 9 items which involve "basic support mechanisms intended to aid the reader in comprehending the text (p. 4)".

The practice version of TOEFL reading comprehension test is utilized with minor changes depending on the research purpose. The test constitutes three reading comprehension passages adapted from TOEFL. The reading comprehension test of 80 marks was conducted to the students for an hour. Depending on the difficulty of the questions and by referring to the instruction of ETS (1997), the scores for every question is decided. The test reliability of TOEFL is .95 (ETS, 1997). A Cronbach's alpha (reliability test) run through SPSS for the current research display an acceptable reliability (.74).

\subsection{Data Collection Procedure}

The researcher administered Reading Comprehension Test (RCT) and the SORS to the students. The students were asked to answer for all the three passages and the questions associated with them. The tests were administered with reference to the guidelines connected with each instrument. The purpose of the study was elucidated both verbally and in writing to all the participants. Finally, they were assured of the confidentiality of the responses.

\subsection{Data Analysis}

The data were analyzed using the SPSS statistical program. Descriptive statistics results were evolved for overall total SORS and all the three subdivisions (Global, Support, and Problem solving) of SORS, RCT scores and Gender. Paired sample t-tests were conducted to compare the significance differences between the three subdivisions global, support, and problem solving reading strategy. Pearson-product moment correlation was performed to study the relationship among the three subdivisions of SORS, total SORS and RCT scores. One-way ANOVA was performed to identity the significant mean difference for all these variables.

\section{Results and Discussion}

\subsection{Overall Reading Strategy Usage}

Results of the SORS administered to the first year engineering students reported medium to high use of reading strategies. The total average use of reading strategies fell under medium level $(\mathrm{M}=3.39)$. The students mostly preferred problem solving strategies $(\mathrm{M}=3.78)$ during academic reading. Next to this, the students preferred using supporting strategy $(M=3.27)$. The least preferred strategy by the students was global strategy $(\mathrm{M}=3.24)$. The paired sample $t$-test results revealed statistically significant difference $(t=12.85)(p=0.00)$ in the three categories of reading strategies and the total reading strategies. Except for global and supporting strategies, all 
other combinations of strategies were statistically significant (see table 1).

Table 1. Descriptive Statistics for the variables and Paired Sample t-Tests for mean difference between the three strategy Categories

\begin{tabular}{lllll}
\hline & Mean & Std. D & Difference & \multicolumn{1}{c}{} \\
\hline Glob. & 3.24 & 3.24 & Prob $>$ Glob & $6.697^{* *}$ \\
Prob. & 3.78 & 3.78 & Prob $>$ Sup & $6.183^{* *}$ \\
Sup. & 3.27 & 3.27 & Sup $>$ Glob & 0.307 \\
TOTAL & 3.39 & 3.39 & & $12.85^{* *}$ \\
\hline
\end{tabular}

Glob (Global Strategy), Prob (Problem Solving Strategy), Sup (Supporting Strategy)

$* \mathrm{p}<0.01$

Among the 30 strategies, 14 strategies fell under high frequency usage level (above $\mathrm{M}=3.5$ ), and 15 strategies fell under medium frequency usage level (below $\mathrm{M}=3.4$ to $\mathrm{M}=2.5$ ). Only one strategy fell under low frequency usage level (below $\mathrm{M}=2.4$ ).

Table 2 explains ranks reported strategy use by individual item mean scores on SORS for the complete sample. Based on the mean scores, the thirty items of the SORS were arranged in descending order from most used to least used. The most used reading strategy by the students was the problem solving strategy 'When text becomes difficult, I re-read it to increase my understanding' $(\mathrm{M}=4.3)$. I try to picture or visualize information to help remember what I read $(M=4.02)$. I adjust my reading speed according to what I am reading $(M=4.02)$. The preferences of the students clearly indicates that the students' employ proper attention to the text that they are reading. The students concentrate more on the text, in order to understand the sequence of meaning embedded in the text. Thus, the students are aware of their comprehension process and are able to manage when their comprehensions break down.

Supporting strategies like 'I think about information in both English and my mother tongue' $(M=2.71)$ and 'I translate from English into my native language' $(M=2.68)$ are least preferred by the students. The problem solving strategy like, 'I stop from time to time and think about what I am reading $(M=2.77)$ is also used the least. This indicates that the students are not utilizing possible techniques, which will enhance their validation of text. The traditional method of teaching at the Indian classrooms may be the reason for least use of these strategies. In the Indian traditional classrooms, students are not encouraged to discuss or employ logic while learning inside the class. Instead, they are instructed to read and memorize the text as such without understanding the meaning or rationale of the text. The lack of rationalizing the text that they are reading minimizes the use of those strategies that will enhance validation and evaluation.

Thus, the overall observation of reading strategy use by the students reveals that the students employ concentration while reading the text, but they are not taking measures to evaluate the meaning of the text that they are reading. Therefore, the analysis reveals that the students overall exhibit characteristics of active strategic readers. This result is consistent with the findings of the previous research (Block, 1986, 1992; Hadwin et al., 2001; Sheorey \& Mokhtari, 2001; Zhang, 2001; Zhang et al., 2008; Zhang \& Wu, 2009). Further, the Indian students as similar to the Chinese students rely on local strategies such as rereading, sentence syntax while reading English texts. 
Table 2. Preferences of Reading Strategy by ESL students

\begin{tabular}{|c|c|c|c|}
\hline $\begin{array}{l}\text { Strategy } \\
\text { category }\end{array}$ & Serial number and statements (as per SORS) & Rank & Mean \\
\hline High-use & $(M=3.5$ or above $)$ & & \\
\hline Prob & 25. When text becomes difficult, I re-read it to increase my understanding. & 1 & 4.3 \\
\hline Prob & 19. I try to picture or visualize information to help remember what I read. & 2 & 4.02 \\
\hline Prob & 11. I adjust my reading speed according to what I am reading. & 3 & 4.02 \\
\hline Prob & 7. I read slowly and carefully to make sure I understand what I am reading. & 4 & 3.87 \\
\hline Prob & 9. I try to get back on track when I lose concentration. & 5 & 3.83 \\
\hline Prob & 14. When text becomes difficult, I pay closer attention to what I am reading. & 6 & 3.83 \\
\hline Sup & 10. I underline or circle information in the text to help me remember it. & 7 & 3.83 \\
\hline Sup & 18. I paraphrase (restate ideas in my own words) to better understand what I read. & 8 & 3.79 \\
\hline Glob & 1. I have a purpose in mind when I read. & 9 & 3.65 \\
\hline Prob & 28. When I read, I guess the meaning of unknown words or phrases. & 10 & 3.61 \\
\hline Sup & 22. I go back and forth in the text to find relationships among ideas in it. & 11 & 3.59 \\
\hline Glob & 3. I think about what I know to help me understand what I read. & 12 & 3.57 \\
\hline Glob & 4. I take an overall view of the text to see what it is about before reading it. & 13 & 3.53 \\
\hline Glob & 24. I try to guess what the content of the text is about when I read. & 14 & 3.51 \\
\hline \multicolumn{4}{|c|}{ 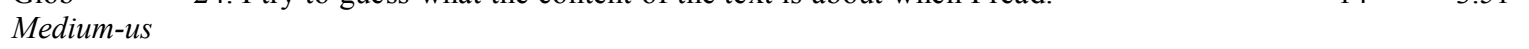 } \\
\hline$e$ & $(M=2.5-3.4)$ & & \\
\hline Sup & 5. When text becomes difficult, I read aloud to help me understand what I read. & 15 & 3.44 \\
\hline Glob & 23. I check my understanding when I come across new information. & 16 & 3.38 \\
\hline Glob & 12. When reading, I decide what to read closely and what to ignore. & 17 & 3.36 \\
\hline Sup & 2. I take notes while reading to help me understand what I read. & 18 & 3.36 \\
\hline Glob & 6. I think about whether the content of the text fits my reading purpose. & 19 & 3.34 \\
\hline Glob & 15. I use tables, figures, and pictures in text to increase my understanding. & 20 & 3.28 \\
\hline Glob & 27. I check to see if my guesses about the text are right or wrong. & 21 & 3.22 \\
\hline Sup & 26. I ask myself questions I like to have answered in the text. & 22 & 3.16 \\
\hline Glob & 17. I use context clues to help me better understand what I am reading. & 23 & 3.1 \\
\hline Glob & 21. I critically analyze and evaluate the information presented in the text. & 24 & 3.06 \\
\hline Sup & 13. I use reference materials (e.g. a dictionary) to help me understand what I read. & 25 & 2.83 \\
\hline Glob & 8. I review the text first by noting its characteristics like length and organization. & 26 & 2.79 \\
\hline Prob & 16. I stop from time to time and think about what I am reading. & 27 & 2.77 \\
\hline Sup & 30. When reading, I think about information in both English and my mother tongue. & 28 & 2.71 \\
\hline Sup & 29. When reading, I translate from English into my native language. & 29 & 2.69 \\
\hline Low-use & $(M=2.4$ or below $)$ & & \\
\hline Glob & 20. I use typographical features like bold face and italics to identify key information. & 30 & 2.38 \\
\hline
\end{tabular}

Glob (Global Strategy), Prob (Problem Solving Strategy), Sup (Supporting Strategy)

\subsection{Reading Strategy Use by Reading Proficiency}

The major purpose of the research is to identify the relationship between the reading strategy and second language reading proficiency. Initially, all the three categories of reading strategies significantly correlates with the Reading Comprehension Test (RCT) score. Similarly, the three categories of reading are significantly correlates with the total (see table 3). The results of the correlation analysis reveal that the reading strategy use moderately correlates with reading proficiency levels. Table 3 shows that the global strategy more significantly correlates with the RCT score $(\mathrm{p}=0.01)$. Both problem solving and supporting strategies significantly correlate with RCT score ( $\mathrm{p}=0.05)$. Thus, the results have favored the finding in other researches (Anderson, 1991; Block, 1992; Zhang, 2002). The analysis of the results reveals that there is a significant relationship between reading strategy use and reading proficiency levels.

The mean difference of these students with various proficiency levels is statistically significant except for supporting strategies (see table 4). Based on the score achieved in the reading comprehension test, the proficiency levels of the students are determined. The sample of low proficiency group mostly used the item in the problem solving strategies 'When text becomes difficult, I pay closer attention to what I am reading' $(\mathrm{M}=3.81)$. The second most preferred item is 'When text becomes difficult, I re-read it to increase my understanding' $(\mathrm{M}=3.6)$. The least preferred items by low proficiency students are 'I use reference materials (e.g. a dictionary) to help me understand what I read' $(\mathrm{M}=2.27)$ and 'I take notes while reading to help me understand what I read' $(\mathrm{M}=2.36)$. The results indicate that the low proficiency students are concentrating while reading, but their comprehension level decreases because of less reference to external materials, which will help them to understand the meaning in the context. Thus, the low proficiency students have problems in using basic elements that aid comprehension. 
Table 3. Correlations among the Three Categories of Reading Strategies, Total Reading Strategies, and the RCT Scores

\begin{tabular}{llllll}
\hline & Mean & Prob & Sup & Total & RCT \\
\hline Glob. & - & & & & \\
Prob. & $.692^{* *}$ & - & & & \\
Sup. & $.666^{* *}$ & $.670^{* *}$ & - & & \\
Total & $.917^{* *}$ & $.872^{* *}$ & $.861^{* *}$ & - & \\
RCT & $.338^{* *}$ & $.338^{*}$ & $.291^{*}$ & $.365^{* *}$ & - \\
\hline
\end{tabular}

Glob (Global Strategy), Prob (Problem Solving Strategy), Sup (Supporting Strategy)

**. Correlation is significant at the 0.01 level (2-tailed).

*. Correlation is significant at the 0.05 level (2-tailed).

The item 'When text becomes difficult, I re-read it to increase my understanding' was more frequently used by both middle proficiency students $(M=4.31)$ and high proficiency students $(M=4.57)$. The least used item by the students of all the proficiency levels is the global strategy 'I use typographical features like bold face and italics to identify key information $(\mathrm{M}=2.38)$. This indicated that the students are not comfortable using this strategy for comprehending the information from the text.

The middle proficiency students least used the items 'I review the text first by noting its characteristics like length and organization' $(M=2.60)$ and 'I ask myself questions I like to have answered in the text'. The results revealed that these middle proficiency students lack evaluation strategies. These students are capable of comprehending the meaning from the text, but they are not efficient in evaluating the text. Thus, the absence of employing these evaluating strategies prevents these students from mastering the text they read.

Table 4. Variation in use of Strategy categories by Reading Proficiency level

\begin{tabular}{|c|c|c|c|c|c|c|c|c|c|}
\hline & \multicolumn{2}{|c|}{ Low } & \multicolumn{2}{|c|}{ Medium } & \multicolumn{2}{|c|}{ High } & \multirow[t]{2}{*}{$\mathrm{F}$} & \multirow[t]{2}{*}{ Sig } & \multirow[t]{2}{*}{ Diff. $^{*}$} \\
\hline & Mean & SD & Mean & SD & Mean & SD & & & \\
\hline Glob & 2.94 & .77 & 3.12 & .62 & 3.54 & .56 & 3.59 & .03 & Low \\
\hline Prob & 3.48 & .82 & 3.61 & .80 & 4.12 & .50 & 3.65 & .03 & Mid \\
\hline Sup & 2.98 & .85 & 3.19 & .69 & 3.50 & .45 & 2.38 & .10 & $<$ \\
\hline Total & 3.10 & .75 & 3.28 & .60 & 3.68 & .41 & 4.21 & .02 & High \\
\hline $\mathrm{RCT}$ & 36 & & 49 & & 68 & & & & \\
\hline
\end{tabular}

Glob (Global Strategy), Prob (Problem Solving Strategy), Sup (Supporting Strategy) $\quad * \mathrm{p}<0.05$

High proficiency students least preferred to use the item 'When reading, I translate from English into my native language' $(M=2.53)$. This result can be interpreted using Pressley (1995) statement that the process of translation slows down the reading speed but bridges the gap while comprehension breaks down. Since, the high proficiency students are good at comprehension, they least use the technique of translation. Moreover, the employment of this technique consumes more time while processing the text. Thus, the high proficiency students more frequently use the strategies that help them to comprehend the text fast.

\subsection{Reading Strategy Use by Gender}

The overall strategy use reveals that both male $(M=3.53)$ and female students $(M=3.99)$ more frequently use problem-solving strategy (see table 5). Consistent with the result of various other studies on gender, the females $(M=3.52)$ employ strategy more frequently when compared to male $(M=3.24)$ students (Poole, 2009; Ehrman and Oxford, 1989; Oxford, 1993; Hong-Nam and Leavell, 2006). Only the mean difference between problem solving strategy is statistically significant $(\mathrm{p}=0.03)$. The mean difference of supporting strategy is also almost statistically significant $(\mathrm{p}=0.6)$. The mean difference of use of global strategy between male and female is not statistically significant. 
Table 5. Variation in use of Strategy categories by gender

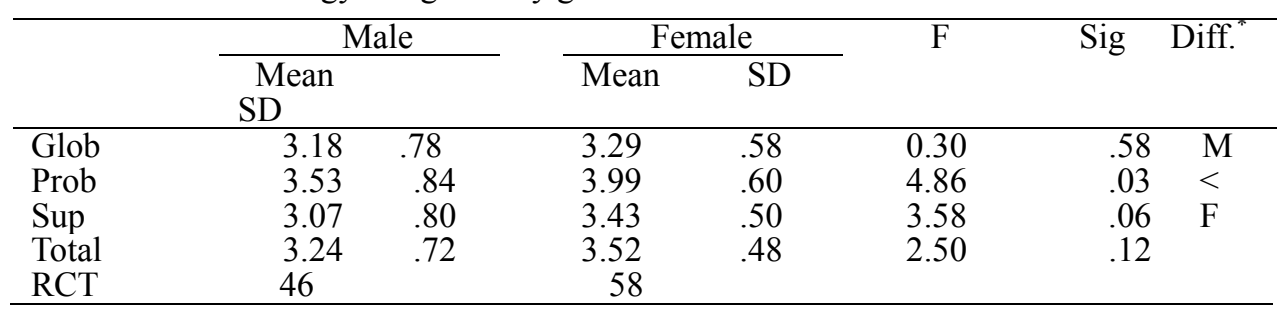

Glob (Global Strategy), Prob (Problem Solving Strategy), Sup (Supporting Strategy) * $\mathrm{p}<0.05$

Female students always used the item 'When text becomes difficult, I re-read it to increase my understanding' (4.51). They more frequently used 'I adjust my reading speed according to what I am reading' $(\mathrm{M}=4.33)$ and 'picture or visualize information' ( $\mathrm{M}=4.22)$. The result can be interpreted through extra reading habits of the females. The background details reveal that the $73 \%$ of the females do extra reading at home. Once the Indian females entered secondary education, they are restricted to play outside the home due to cultural reasons. Therefore, the females may engage themselves in extra reading habits like reading newspaper, novels and short stories. The regular reading habits might have consciously increased the awareness and employment of the reading strategies as explained in various researches on extensive reading (Al-Nujaidi, 2003; Carrell \& Carson, 1997).

Males more frequently used the item 'I try to guess what the content of the text is about when I read' $(M=3.86)$ and least used the item 'I underline or circle information in the text to help me remember it' $(\mathrm{M}=3.63)$. It seems that the male students use coherence strategies more frequently while reading. Only $38 \%$ of the male students engage themselves in extra reading; especially they choose to read newspaper and avoid reading novels and short stories. Thus, it is clear that extra reading activities helped females to enhance their reading strategy use and their reading abilities.

\section{Conclusion}

The overall reading strategy use of Indian ESL students exhibits characteristics of active strategic readers. This reports that the ESL readers are consciously employing a wide variety of reading strategies similar to that of native readers of English, in order to achieve comprehension. As mentioned in previous researches, the students could have possibly transferred the awareness of the reading strategies from the L1 reading strategy to ESL reading (Grabe \& Stoller, 2002; Zhang, 2008). Although the students use these strategies actively, how effectively they understand each strategy and use them is dubious. Therefore, it is necessary to focus on teaching these reading strategies explicitly for the students (Hudson, 2007). It is identified that extra reading habits have influenced on the reading strategy use of the female students. The male students have less reading habits, which may be a reason for less employment of strategy than that of females. This result is consistent with that of other researches on ESL strategy use and reading (Hudson, 2007; Zhang \& Wu, 2009). Thus, the students' at the undergraduate level must be exposed to English in various modalities, which may enhance their strategy awareness and use.

The study has some realistic implication for ESL reading strategy instruction in Indian undergraduate classrooms. First, the results of the study reveal moderate correlation between reading strategy use and reading proficiency levels. All the three strategies of reading equally correlate and contribute to the effective comprehension of the text. Although Indian education system has adapted western method of teaching, there are cultural difference between the east and the west. Such variation in social cultural factors may be the reason for moderate correlation between reading strategy use and reading proficiency levels. There may be specific strategies and technique that the Indian students might use other than the once mentioned in SORS, which ones need to be explored.

Second, the high proficiency students frequently use reading strategies. They are good at choosing appropriate strategies for better planning and monitoring reading comprehension. By contrast, low proficiency students used inappropriate strategies, which may be the reason for their unsuccessful comprehension. Therefore, it can be assumed that low proficiency students will be benefited from the explicit teaching of reading strategy use. Moreover, a course in strategic reading will help students of all proficiency levels to think about their comprehension process, identify their strengths and weaknesses in reading, and so can take remedial measures. Many studies have used think aloud protocol for strategy training that had positive effects on EFL and ESL learners (Carrell et al., 1989; Hudson, 1998; Rasekh \& Ranjbary, 2003). The teacher has to teach both the 
comprehension as well as the reading strategies that the student employs for comprehending meaning in the text.

The current study suggests collaborative learning as an extension of think aloud protocol, which will facilitate the students to speak out their reading process to their peers. Collaborative learning encourages group learning of the students. Instead of thinking aloud, group learning provides scope for the students to describe their reading process in words to their group members and to explain the reason for choosing a particular strategy to deduce information from the text.

To initiate collaborative learning on reading strategy, the students have to be divided into several groups. It is necessary that a group must constitute students with various proficiency levels and gender, so that it will be beneficial for the students using inappropriate strategy. For example, the Female students mostly visualize information from the text to remember what they read. In case like this, the female participant may be asked to reason out to the group on how they visualize a concept while reading and why they use this strategy while reading. Firstly, this practice will enhance the awareness among female students those who use this particular strategy of 'visualizing' while reading. Secondly, the group members listening to the experience of 'visualizing the text' by the female student will be greatly benefited. Moreover, through sharing of reading process to the peers, it is possible to identify the individual difference while 'visualizing the same text'. Not every female student will visualize a text in the same way. Thus, the teacher must efficiently co-ordinate within the groups. The effectiveness in the teachers' instruction will enable the students to indulge in the collaborative learning successfully.

\section{Acknowledgments}

I would like to thank Dr. N. Ramani, my supervisor for proof reading the article.

\section{Reference}

Alderson, J. C. (1984). Reading in a foreign language: A reading problem or a language problem? In J.C. Alderson, \& A.H. Urquhart (Eds.), Reading in a foreign language (pp. 1-27). New York: Longman.

Al-Nujaidi, A. (2003). The relationship between vocabulary size, reading strategies, and reading comprehension of EFL learners in Saudi Arabia. Unpublished doctoral dissertation, Oklahoma State University-Stillwater.

Anderson, N. (1991). Individual differences in strategy use in second language reading and testing. Modern Language Journal, 75, 460-72. http://dx.doi.org/10.2307/329495

Block, E. L. (1986). The comprehension strategies of second language readers. TESOL Quarterly, 20, 463-494. http://dx.doi.org/10.2307/3586295

Block, E. L. (1992). See how they read: Comprehension monitoring of L1 and L2 readers. TESOL Quarterly, 26, 319-342. http://dx.doi.org/10.2307/3587008

Brantmeier, C. (2002). Second language reading strategy research at the secondary and university levels: Variations, disparities and generalizability. The Reading Matrix: An International Online Journal, 3(2), 1-14. Retrieved from: http://www.readingmatrix.com/current.html

Carrell, P. (1989). Metacognitive awareness and second language reading. Modern Language Journal, 73, 121-13. http://dx.doi.org/10.2307/326568

Carrell, P. L. (1991). Second language reading: Reading ability or language proficiency? Applied Linguistics, 12, 159-179.

Carrell, P., \& Carson, J. G. (1997). Extensive and Intensive Reading in an EAP Setting. English for Specific Purposes, 16, 47-60. http://dx.doi.org/10.1016/S0889-4906(96)00031-2

Carrell, P., Pharis, B., \& Liberto, J. (1989). Metacognitive strategy training for ESL reading. TESOL Quarterly, 23, 647-678. http://dx.doi.org/10.2307/3587536

Cheng, C. (1998). A descriptive study of reading strategies used by Chinese ESL students from Taiwan, R. 0. C. Unpublished doctoral dissertation, University of Kansas-Lawrence.

Cheng, C. (2000). The relationship between metacognitive factors and reading ability. Paper presented at the proceedings of the seventeenth conference on English Teaching and Learning in the Republic of China, Taipei.

Chern, C. L. (1994). Chinese readers' metacognitive awareness in reading Chinese and English. In N. Bird (Ed.), Language and learning (pp. 401-421). Hong Kong:Institute of Language in Education.

Clarke, M. (1979). Reading in Spanish and English. Language Learning, 29, 121-150. 
Cohen, A. (1990). Language learning: Insights for learners, teachers, and researchers. Boston: Heinle \& Heinle Publishers.

Cziko, G. A. (1978). Differences in first- and second-language reading: The use of syntactic, semantic and discourse constraints. The Canadian Modern Language Review, 34, 473-489.

Educational Testing Service (ETS). (1997). TOEFL test and score data summary (Manual). Princeton, NJ.

Flavell, J. (1979). Metacognition and cognitive monitoring: A new area of cognitive developmental inquiry. American Psychologist, 34, 906-911. http://dx.doi.org/10.1037//0003-066X.34.10.906

Garner, R. (1987). Metacognition and reading comprehension. Norwood, NJ: Ablex.

Grabe, W., \& Stoller, F. L. (2002). Teaching and researching reading. Harlow, England: Pearson Education.

Haas, C., \& Flower, L. (1988). Rhetorical reading strategies and the construction of meaning. College Composition and Communication, 39, 167-83.

Hadwin, A. F., Winne, P. H., Stockley, D. B., Nesbit, J. C., \& Woszczyna, C. (2001). Context moderates students' self-reports about how they study. Journal of Educational Psychology, 93, 477-488. http://dx.doi.org/10.1037//0022-0663.93.3.477

Hsu, L. (2003). A study of relationships between feeling of knowing about English reading strategy use and reading comprehension of Taiwanese college students. National Changhua University of Education.

Hudson, T. (1998). Theoretical perspectives on reading. Annual Review of Applied Linguistics, 18, 43-60. http://dx.doi.org/10.1017/S0267190500003470

Hudson, T. (2007). Teaching second language reading. Oxford, England: Oxford University Press.

Leavell, G. Hong-Nam, Kyungsim. (2006). Language learning strategy use of ESL students in an intensive English learning context. System, 34, 399-415.

Macaro, E. (2001). Learning strategies in foreign and second language classroom. London: Continuum International.

Macaro, E., \& Erler, L. (2008). Raising the achievement of young-beginner readers of French through strategy instruction. Applied Linguistics, 29, 90-119. http://dx.doi.org/10.1093/applin/amm023

McDough, S. (1995). Strategy and skill in learning a foreign language. London: Edward Arnold.

Mokhtari, K., \& Sheorey, R. (2002). Measuring ESL students' awareness of reading strategies. Journal of Developmental Education, 25(3), 2-10.

Oxford, R. L. (1993). Instructional implications of gender difference in language learning styles and strategies. Applied Language Learning, 4, 65-94.

Oxford, R. L., \& Ehrman, M. (1995). Adult's language learning strategies in an intensive foreign language program in the United States. System, 23(3), 359-386.

Poole, A. (2009). The Reading Strategies Used by Male and Female Colombian University Students. PROFILE, $11,29-40$.

Pressley, M. (2002). Metacognition and self-regulated comprehension. In A. E. Farstrup, \& S. J. Samuels (Eds.), What research has to say about reading instruction (pp. 219-309). Newark, DE: International Reading Association. http://dx.doi.org/10.1598/0872071774.13

Rasekh, A. E., \& Ranjbary, R. (2003). Metacognitive strategy training for vocabulary learning. TESL-EJ, 7(2).

Sheorey, R., \& Mokhtari, K. (2001). Differences in the metacognitive awareness of reading strategies among native and nonnative readers. System, 29(4), 431-449.

Susser, B., \& Robb, T. (1990). Extensive Reading Instruction: Research and Procedure. JALT Journal, 12, 161-185.

Wu, W. (2002). Taiwanese junior high school students' metacognitive awareness in reading Chinese and English. National Taiwan Normal University.

Wu, A., \& Zhang, L. J. (2009). Chinese senior high school EFL students' metacognitive awareness and reading-strategy use. Reading in a Foreign Language, 21(1), 37-59.

Zhang, L. J. (2001). Awareness in reading: EFL students' metacognitive knowledge of reading strategies in an acquisition-poor environment. Language Awareness, 10, 268-288. 
Zhang, L. J. (2002). Exploring EFL reading as a metacognitive experience: Reader awareness and reading performance. Asian Journal of English Language Teaching, 12, 65-90.

Zhang, L. J. (2008). Constructivist pedagogy in strategic reading instruction: Exploring pathways to learner development in the English as a second language (ESL) classrooms. Instructional Science: An International Journal of the Learning Sciences, 36, 89-116. http://dx.doi.org/10.1007/s11251-007-9025-6

Zhang, L. J., \& Annul, S. (2008). The role of vocabulary in reading comprehension: The case of secondary school students learning English in Singapore. RELC Journal: A Journal of Language Teaching and Research, 39, 51-76. 